\title{
Jóvenes, participación y espacios de poder en organizaciones de Lima Metropolitana. Aproximaciones rumbo al Bicentenario
}

Sección ESTUDIOS

RECIBIDO: $1 / 10 / 2020$

APROBADO: 15/11/2020

PUBLICADO ONLINE: $18 / 12 / 2020$

\author{
Franco Evans Morales \\ Universidad Nacional Mayor de San Marcos \\ 10150024@unmsm.edu.pe \\ https://orcid.org/0000-0003-4523-7872
}

\section{RESUMEN}

El artículo considera a las y los jóvenes actores estratégicos para el desarrollo, quienes se movilizan entre lógicas de emancipación e integración subordinada; es por ello, que se reconstruye a la juventud en una condición desigual y diferenciada cuyas posiciones sociales, sustentadas en relaciones de poder frente al mundo adultocéntrico, impactan en las dinámicas de participación juvenil organizada. En visto de ello, y a través de entrevistas, se busca analizar a este grupo y sus significados de participación organizada; analizar las formas de relación entre jóvenes organizados y autoridades políticas; y reflexionar sobre los espacios institucionalizados de participación juvenil. Se rescata que las y los jóvenes se autodefinen y definen a otros como sujetos juveniles según el sistema de relaciones de poder en que se insertan; que la participación es un recurso para generar cambios en el entorno y que existen barreras institucionales para la relación con autoridades.

PALABRAS CLAVE: jóvenes; participación; organizaciones; autoridades.

\section{Youth, participation, and power spaces in organizations in Metropolitan Lima. Approaches to the Bicentennial}

\begin{abstract}
The article considers young people as strategic actors for development that move between logics of emancipation and subordinate integration, therefore, youth is reconstructed as an unequal and differentiated condition whose social positions are sustained in power relations with the world adult-centric that impact on the dynamics of organized youth participation. For this purpose, through interviews, the aim is to understand young people and their meanings of organized participation, analyze the forms of relationship between organized young people and political authorities and reflect on the institutionalized spaces of youth participation. It is rescued that young people define themselves and define others as youthful subjects according to the system of power relations in which they are inserted, that participation is a resource to generate changes in the environment and that there are institutional barriers to the relationship with authorities.
\end{abstract}

KEYWORDS: Youth; participation; organizations; authorities. 


\section{Introducción}

\section{A} puertas del Bicentenario de la Independencia del Perú, hablar de juventudes como categoría analítica o de las y los jóvenes como grupos sociales diferenciados, requiere abordajes sistemáticos que abarque toda complejidad para su comprensión. Las sensibilidades expresadas en la vida cotidiana, así como la producción de sus manifestaciones socioculturales repercuten en las formas cómo, desde el Estado, se construye su definición, así como los vínculos de relación y autoidentificación del quehacer juvenil desde las propias juventudes organizadas y no organizadas. Las y los jóvenes se mueven entre dinámicas de integración y emancipación de manera permanente, así como en relaciones tensas entre la proscripción social y la anticipación moral (Alvarado, Martínez y Muñoz, 2009); específicamente esta situación permite visibilizar la agencia humana para subvertir el estado del orden existente, aquella estructura social incapaz de acoger las múltiples demandas que las y los jóvenes expresan a través de diversos mecanismos institucionales, informales o prácticos dentro de sus territorios, impulsados por la búsqueda de integración a los procesos de desarrollo que permita frenar la exclusión, la pobreza y la marginalidad.

Las y los jóvenes se desenvuelven en un espacio-tiempo concreto y su transformación está vinculada a las condiciones estructurales en que se desenvuelven - aunque no de manera secuencial sino muchas veces de manera fragmentada y con trayectorias flexibles dentro de la estructura social que los alberga-. Esta fragmentación de las cotidianeidades juveniles implica la oportunidad de generar conocimientos sobre las expresiones de las y los jóvenes, así como formar visiones integrales y comprensivas que tomen en cuenta la especificidad de la condición juvenil y sus patrones de relación con lo generacional, sea con adultos u otros grupos sociales; sin embargo, también representa una oportunidad para generar abordajes que rompan con el individualismo (Alvarado, Borelli y Vommaro, 2012). Al indagar sus sentidos de pertenencia al territorio y producción de sentidos alrededor de formas organizadas de participación, estos marcos de acción colectiva permiten liberar sistemas de creencias y prácticas organizadas que ponen en tensión las relaciones de poder entre las y los jóvenes y las instituciones del aparato estatal, así como dentro de sus propios territorios. Por otro lado, la legitimidad existencial de las y los jóvenes se redefine constantemente según la perspectiva y enfoques de definición que se les brinde, especialmente desde el mundo adulto.

Los procesos de modernización económica, social y política que se dio en Europa hacia finales del siglo XVIII e inicios del siglo XIX, tuvieron efecto en la con- 
formación de las y los jóvenes como grupo social específico (Souto, 2007), ya que a través del Estado moderno se configuraron prácticas exclusivas para integrarlos a determinadas instituciones de socialización, lo que originó que sean definidos bajo relaciones de dependencia en donde debían seguir reglamentaciones impuestas por el mundo adulto, no obstante, también les permitió autonomías hacia la transición, esto quiere decir que las y los jóvenes fueron identificados bajo perfiles específicos que les proporcionaron un margen para organizarse en espacios como la familia, la escuela o las actividades productivas. Todo este sistema moderno tuvo como finalidad la transición hacia la vida adulta caracterizada por el acceso al mercado laboral, la conformación de una familia nuclear, así como la independencia económica y social.

Las disciplinas científicas no han sido externas a los procesos de definición y representación de lo joven, tales caracterizaciones abordaron una parte de la compleja realidad juvenil según sus presupuestos teóricos y permitieron generar reflexiones y abordajes desde las instituciones estatales y el mundo adulto como forma de integración a los procesos de desarrollo. De la misma forma, los estudios políticos abordaron a las juventudes en su vínculo con lo público y con el poder a través de varias tendencias, sea desde las formas tradicionales de participación a través de mecanismos electorales; la construcción de identidades políticas a través de los movimientos juveniles; los procesos de participación ligados a la democratización del poder; la incidencia dentro de las políticas públicas; y las mediaciones culturales en la construcción de la acción política en las juventudes (Alvarado et al., 2012).

Por otro lado, existen diversos criterios para la definición de las juventudes que han pretendido establecerse como paradigmas para la generación de consensos; sin embargo, la falta de claridad analítica y la integración de estos para comprender la complejidad de sus vidas no les permitió tener abordajes claros. Desde considerar a las y los jóvenes como grupo demográfico cuyo criterio de diferenciación hacia otros grupos sociales es la edad, pasando por pensar a las juventudes como un conjunto de actitudes hacia la vida caracterizadas por sus estados de ánimo, inclusive se considera a la juventud como una etapa de vida distinguible de otros como la niñez y la vida adulta (Duarte, 2000), esta última mirada evidencia patrones de comportamientos específicos y características socioculturales propias de las juventudes; sin embargo, es una perspectiva que privilegia la preparación o transición hacia la vida productiva y reproductiva de la adultez (Castellanos, 2011) como algo estable y duradero, obviando la perspectiva generacional que las juventudes pueden construir a partir de sus propios contextos específicos como grupos heterogéneos con demandas diferentes y no como un simple rito de paso. 
Ahora, este paradigma de la transición juvenil ha ido cambiando, no es homogénea, ya no representa una secuencia lineal para reproducir lo cultural y socialmente establecido (Dávila y Ghiardo, 2011) pues no se pasa de manera directa e irreversible hacia el sistema educativo o al mercado laboral y tampoco al proceso de conformación de la familia y la individualización material y económica; ahora existen procesos diversos para hacerse joven con otras estructuras, secuencias y órdenes sociales que no constituyen una linealidad, sino que muchas veces conviven y son simultáneas. También existe un paradigma que considera a las y los jóvenes como la generación futura o reserva moral de la sociedad, donde se niega su condición presente de joven y se crea una institucionalidad de moratoria social (Taguenca, 2009) para que puedan prepararse y formar parte de los procesos de reproducción social.

Sin embargo, existen otras perspectivas alternativas que indagan las potencialidades y estrategias para el desarrollo por parte de las y los jóvenes como sujetos específicos que construyen su identidad en el presente (Taguenca, 2009). Precisamente no se pretende considerar a las y los jóvenes como grupos autoconstruidos y sin vínculos de relación con sus pares del entorno o con otros grupos generacionales, sino reconocerlos como actores socioculturales heterogéneos con demandas específicas y en tensión con las estructuras del adultocentrismo que son «depositarias de la normatividad y la estabilidad social» (Alvarado et al., 2009, p. 93) o en palabras de Bourdieu (2002), en espacios sociales donde la frontera entre jóvenes y adultos representa un objeto de lucha. Este tipo de segmentación y diferenciación de las juventudes se sustenta en su relación con otros significantes (Taguenca, 2009), produciendo sus propias estrategias de relación dentro del espacio en el que intervienen y poniendo en tensión los mecanismos que los adultos utilizan para deslegitimar y subordinar las dinámicas juveniles.

Las juventudes deben lidiar, por un lado con procesar las contradicciones presentadas por su propia condición juvenil y, por otro lado, contra lo socialmente determinado desde el mundo adulto, poniendo en constante tensión las estructuras normativas del «deber ser» impuestas por el adultocentrismo, entendiendo que la juventud es una categoría analítica que permite examinar sus acciones desde lo múltiple y contingente (Taguenca, 2009), no solo como sujetos dentro de una cohorte de edad sino también dentro de sistemas de poder establecidos.

En esta investigación se plantea la salida analítica propuesta por Castellanos (2011) y pensar a la juventud como una «condición desigual y diferenciada» (p. 161), articulada por distintos elementos y trayectorias como experiencia organizacional, clase social, trayectorias educativas y laborales, así como sistemas de producción de 
la cultura y la política. Pensar a la juventud como condición implica situar a las y los jóvenes en un conjunto de tramas de significados y posiciones sociales históricamente diferenciadas, esto quiere decir que dichas posiciones no son disposiciones particulares por donde las y los jóvenes pasan en el momento, sino que son resultado de estructuras de poder y en estas correlaciones de fuerzas contradictorias es que se construyen universos sociales que localizan a los sujetos juveniles. De la misma forma, las trayectorias juveniles son el reflejo de las estructuras y procesos sociales (Dávila, Ghiardo y Medrano, 2008) ubicadas en el conjunto de posiciones sociales que ocupan los sujetos dentro de la estructura y, que a diferencia de la transición juvenil, no es una secuencia de carácter biológico para formar a la nueva generación de individuos adultos, sino un orden no secuencial e histórico donde la condición juvenil es producto y a la vez productora de disposiciones subjetivas de ser joven. El espacio social donde se desenvuelven las y los jóvenes es un espacio de relaciones que combina diferentes posiciones sociales y adquiere significado en su vínculo con los demás, en donde las formas de pensar y ver el mundo, así como las disposiciones de acción están basadas en las posiciones de clase que se ubican en el espacio (Dávila y Ghiardo, 2011).

Esto lleva a reflexionar a las y los jóvenes en su papel como actores estratégicos para el desarrollo y en su vinculación con la vida pública desde diversas trayectorias juveniles. Serna (citado en Balardini, 2005) indica algunas de las características novedosas en la forma de participación juvenil dentro del ámbito público, que abarcan desde la búsqueda de objetivos concretos a corto y mediano plazo vinculados a la vida cotidiana, la recuperación del rol del individuo y la autonomía dentro de organizaciones, hasta formatos de trabajo a través de mesas juveniles o redes con dinámicas horizontales y de cooperación. Los cambios, como participación juvenil, se inscriben en las formas de producción de la estructura social en que se desenvuelven y en las estrategias para relacionarse con el poder dentro del contexto latinoamericano; en el Perú, por ejemplo, se ha construido la imagen del joven rebelde, revolucionario y politizado durante los años setenta; la imagen del joven standard (Sandoval, 2000) que privilegia el consumo e intereses individuales durante los años noventa y, en este siglo, la del joven inserto en redes informacionales que visibiliza sus derechos y se organiza colectivamente a través del espacio público.

Esta investigación considera a la participación juvenil como un mecanismo liberador de potencialidades inhibidas (Hopenhayn, 1988) que toma a la o el joven menos como objeto y más como sujeto que le permita ser protagonista (Krauskopf, 2000) para enfrentar el adultocentrismo, ganar control sobre su proyecto de vida, poseer reconocimiento individual y colectivo, así como integrarse a los procesos de 
desarrollo. La construcción de estos procesos dentro de lo público requiere soportes, en donde los elementos centrales son el poder como posibilidad y la acción colectiva (Botero y Torres, 2008); y es aquí donde resalta la importancia de las organizaciones, consideradas como el «conjunto interrelacionado de actividades entre dos o más personas que interactúan para procurar el logro de un objetivo común, a través de una estructura de roles y funciones, y en una división del trabajo» (Krieger, 2003, p. 3). De esta manera la o el joven no se sostiene de manera individual, sino que a través de formas específicas de organización dirige su accionar hacia fines y objetivos determinados, muchos de estos dentro de un territorio.

La condición juvenil diferenciada imprime que las organizaciones o colectivos juveniles sean formas flexibles de agrupamiento, con una estructura organizacional horizontal vinculada a la búsqueda de objetivos de la vida cotidiana y con una proyección comunitaria (Garcés, 2010), otras organizaciones juveniles buscan despertar sensibilidades y acceso a conocimiento e información (Vega y Escalante, 2007), también existen aquellas más políticas que como desafección al sistema de representación política tradicional construyen prácticas de autogestión, asambleísmo y pluralismo en donde cobra especial fuerza la culturalización de la política (Valenzuela, 2007); además existen debates en torno al significado juvenil de estas organizaciones y/o colectivos; por ello, el reto está en descubrir los mecanismos que le brindan identidad desde lo joven o, por el contrario, si se han desplazado hacia identidades más comunitarias y territoriales (Ortiz-Ruiz, 2016).

En el sistema nacional existen diferentes mecanismos de participación ciudadana para la vigilancia y la incidencia política (rendición de cuentas, referéndum, cabildos abiertos, asambleas públicas) y la asignación de recursos económicos y proyectos para la comunidad (presupuestos participativos). El principal mecanismo estatal de participación juvenil en el Perú son los Consejos de Juventud, que pueden ser distritales, provinciales y regionales. Estos son órganos de representación, consulta y concertación de las juventudes que contribuyen al diálogo entre organizaciones juveniles e instituciones públicas y privadas de los gobiernos locales, provinciales y regionales (SENAJU, 2013). Según el Centro de Desarrollo de la OCDE (2017) en principio los Consejos de Juventud deben ser instancias autónomas promovidas por las autoridades políticas para involucrar a las y los jóvenes en las políticas públicas, sin embargo, en la práctica son espacios creados voluntariamente por los gobiernos locales, provinciales y regionales cuyas atribuciones, competencias y funciones de representación dependen del horizonte político de estos últimos.

Tomando todas estas consideraciones, esta investigación reflexiona sobre los siguientes tres aspectos: el primero, busca analizar a las y los jóvenes y sus signifi- 
cados de participación organizada; el segundo, analiza las formas de relación entre jóvenes organizados y autoridades políticas; y el tercer aspecto reflexiona sobre los espacios institucionalizados de participación juvenil.

\section{Metodología}

La presente investigación utilizó el método comprensivo para alcanzar la comprensión óptima del problema, por ello se toma la propuesta de Gurdián-Fernández (2007) para quién este método busca «comprender una conducta humana, como encuentro de dos intencionalidades, la del sujeto conocedor y la del sujeto conocido» (p. 157), y es que las personas necesitan ser comprendidas en sus propios contextos sociales y culturales, para ello el investigador tiene que captar las relaciones internas de los sujetos de estudio y ser capaz de penetrar la intimidad del ser humano.

La técnica de recolección empleada fue la entrevista a profundidad entendida como el encuentro cara a cara entre investigador e investigado para conocer la opinión o perspectiva que el sujeto tiene respecto de su experiencia vivida (Campoy y Gomes, 2015), allí las preguntas fueron abiertas y sin categorías preestablecidas. Las entrevistas tuvieron una duración aproximada entre 40 a 60 minutos y fueron aplicadas en un centro comercial del distrito de Cercado de Lima.

Para el análisis de los resultados se utilizó la técnica de la reducción fenomenológica propuesta por Aguirre-García y Jaramillo-Echeverri (2012), esta técnica consiste en que el investigador "pasa de una actitud natural a un mundo dado como fenómeno en la conciencia» (p. 59). Por ello se pasó a describir cada una de las vivencias hasta lograr su esencia, o sea describir la estructura que hace posible su constitución como sujetos de estudio.

Esta investigación cualitativa sustenta sus hallazgos en tres sustantivos estructurantes del método comprensivo. Souza (2010) los califica como «experiencia» que es la realidad concreta vivida como primera fuente y está rodeada de antecedentes históricos y sociales. «La vivencia» como el contenido psíquico que las personas ponen cuando interpretan la experiencia y «el significado» se refiere al sentido subjetivo que los individuos atribuyen a la realidad cotidiana y a su interpretación de la vivencia.

Durante el año 2016 el investigador trabajó en la Secretaría Nacional de la Juventud (SENAJU) como especialista en materia de juventudes. Durante ese período se desarrollaron encuentros juveniles y programas de fortalecimientos de capacidades dirigidos a jóvenes de organizaciones sociales, luego de varios meses 
el investigador pudo generar vínculos de confianza, reconocimiento y trato con las y los jóvenes participantes de estos programas.

Para fines de esta investigación piloto se seleccionaron cinco organizaciones juveniles participantes de los programas e inscritas en el Registro Nacional de Organizaciones Juveniles de SENAJU, dichas organizaciones seleccionadas pertenecen a diferentes campos de acción: medio ambiente, derechos sexuales y reproductivos y culturales. También fue considerado el componente territorial, pues se buscó que los campos de intervención de las organizaciones juveniles sean descentralizados: Miraflores y Cercado de Lima en Lima Centro, Ate Vitarte en Lima Este y San Martín de Porres en Lima Norte.

Las y los jóvenes entrevistados fueron presidentes(as), coordinadores(as) e integrantes con mayor tiempo en sus respectivas organizaciones juveniles durante el año 2016, ellas y ellos estaban en condiciones de brindar experiencias vividas más intensas en organización. Se buscó que las y los jóvenes organizados tengan entre 15 a 29 años y sus trayectorias educativas sean diversas entre sí para tener una lectura heterogénea sobre la experiencia individual de participación juvenil. A continuación se muestran las características de las y los 5 jóvenes seleccionados, por criterios de anonimato y a solicitud de las y los entrevistados solo se darán a conocer sus letras iniciales.

Tabla 1. Características de las y los jóvenes entrevistados

\begin{tabular}{|c|c|c|c|c|c|c|c|}
\hline Nombre & Sexo & Edad & $\begin{array}{c}\text { Carrera } \\
\text { profesional }\end{array}$ & $\begin{array}{l}\text { Centro de } \\
\text { estudios }\end{array}$ & $\begin{array}{l}\text { Organización } \\
\text { juvenil }\end{array}$ & $\begin{array}{c}\text { Tipo de } \\
\text { organización }\end{array}$ & $\begin{array}{l}\text { Distrito de } \\
\text { intervención }\end{array}$ \\
\hline F. H & Mujer & 22 & $\begin{array}{c}\text { Biología } \\
\text { marina }\end{array}$ & $\begin{array}{l}\text { Universidad } \\
\text { privada }\end{array}$ & W.C.B.H. & $\begin{array}{c}\text { Medio } \\
\text { ambiental }\end{array}$ & Miraflores \\
\hline J.C. & Hombre & 26 & $\begin{array}{l}\text { Ciencia } \\
\text { política }\end{array}$ & $\begin{array}{l}\text { Universidad } \\
\text { privada }\end{array}$ & R.D.S. & $\begin{array}{l}\text { L.G.T.B.I./ } \\
\text { Derechos } \\
\text { sexuales y } \\
\text { reproductivos }\end{array}$ & $\begin{array}{c}\text { Cercado de } \\
\text { Lima }\end{array}$ \\
\hline S. Q. & Hombre & 18 & $\begin{array}{l}\text { Ciencias de la } \\
\text { comunicación }\end{array}$ & $\begin{array}{l}\text { Universidad } \\
\text { privada }\end{array}$ & K.S.C. & Cultural & Ate Vitarte \\
\hline L.T. & Hombre & 20 & Farmacia & $\begin{array}{l}\text { Instituto } \\
\text { técnico } \\
\text { privado }\end{array}$ & J.E.C.I. & $\begin{array}{l}\text { L.G.T.B.I./ } \\
\text { Derechos } \\
\text { sexuales y } \\
\text { reproductivos }\end{array}$ & $\begin{array}{c}\text { San Martín } \\
\text { de Porres }\end{array}$ \\
\hline L.S. & Mujer & 21 & Psicología & $\begin{array}{l}\text { Universidad } \\
\text { pública }\end{array}$ & R.N.J. & $\begin{array}{l}\text { L.G.T.B.I./ } \\
\text { Derechos } \\
\text { sexuales y } \\
\text { reproductivos }\end{array}$ & $\begin{array}{c}\text { Cercado de } \\
\text { Lima }\end{array}$ \\
\hline
\end{tabular}

Fuente: Elaboración propia. 


\section{Resultados}

\section{Jóvenes y significados de participación organizada}

\section{a. La construcción del sujeto juvenil}

Las y los jóvenes viven diferentes situaciones dentro de su vida cotidiana, se autodefinen en base a sus propias características y sus estrategias de intervención en la vida pública; de la misma forma, los enfoques de definición que se construyen sobre las y los jóvenes vienen desde experiencias personales y colectivas, así como desde su cercanía o lejanía con el aparato estatal entendido como el conjunto de instituciones públicas que en teoría deberían tener un vínculo de relación a través de sus servicios dirigidos a las juventudes. A lo largo del texto se identifican diferentes perfiles de jóvenes: sujetos que viven del presente; sujetos en constante aprendizaje, sujetos jóvenes en situación de moratoria; jóvenes que perciben al Estado como una institución portadora de deficiencias institucionales; jóvenes vistos como sujetos subordinados a las lógicas adultocéntricas; jóvenes como sujetos en transición y quienes se pueden autodefinir como sujetos en búsqueda de protagonismo y cambio de sus entornos.

Entrevistador: ¿Cómo ves la situación de los jóvenes que viven en tu distrito? F.H.: Creo que la gente está estresada, básicamente piensan en el día a día. No está mal, pero no se piensa a largo plazo, o sea, vivo en el día de hoy que no está mal, pero no pienso en las consecuencias que trae lo que yo hago [...].

Como se describe en el testimonio anterior, existen diferentes perspectivas sobre el quehacer juvenil, en él se hace referencia a las y los jóvenes no organizados, cuyas experiencias de vida se expresan en las actividades del día a día y en el corto plazo, allí no se emite un juicio de valor negativo; sin embargo, denota la deficiencias al largo plazo, específicamente en las trayectorias futuras que la o el joven puede tener y cómo esa situación tendrá impacto en su vida individual y colectiva, así como en la acción colectiva o la participación en espacios territoriales organizados.

J.C. [...] creo que lo que más les gusta a los jóvenes es salir a la calle a protestar y de esa manera hacerse notar, pero desde lo personal pienso que no es lo más estratégico, pienso que la mayoría de los jóvenes de mi edad tienen bastante el pensamiento lúdico. 
S.Q.: Lamentablemente no se ve mucho; muchos jóvenes prefieren irse a fiestas, pasar tiempo con sus amigos. y trabajar en el tema de organizaciones juveniles o participación política no les interesa mucho porque algunos les aburre o sienten que no ganan nada con eso, eso es lo que dicen muchos jóvenes. Ahí está nuestra labor como organización, la de buscar nuevas formas de atraer para que les interese.

J.C. y S.Q. realizan una crítica que vincula a las y los jóvenes con el desinterés hacia la participación en organizaciones o asociaciones juveniles, para ambos una de las razones es que las y los jóvenes tienen otro tipo de preferencias como la asistencia a fiestas, el uso del tiempo libre con las amistades o la indiferencia hacia la organizaciones juveniles y el trabajo en las comunidades. Es lo que específicamente menciona J.C. cuando se refiere a «pensamiento lúdico», para él las y los jóvenes solo buscan la diversión, lo ameno y los propios intereses de la edad juvenil. No obstante, también existe la asociación de juventud con apatía hacia las organizaciones sociales, puesto que según testimonios recogidos, dichos espacios no son considerados como prioridad para las y los jóvenes dentro de su desarrollo individual y colectivo, y no reciben réditos ni beneficios; sin embargo, el reto está en construir incentivos simbólicos, sensibilidades y elementos atractivos que permitan a las organizaciones adherir las heterogéneas demandas juveniles.

J.C.: [...] pienso que se puede incidir políticamente, conversar con los que toman decisiones. Veo mucha resistencia a ser parte del Estado por parte de los nuevos jóvenes que se agrupan o en trabajar en alguna institución pública; piensan que el Estado los mata o no les reconocen sus derechos, pero si van a seguir pensando de esa manera o no ven estrategias de meterse adentro, nunca van a ser tomadores de decisiones [...].

Otra visión crítica de las y los jóvenes es aquella que los toma como sujetos desconfiados del aparato estatal y sus instituciones, pues al ser invisibilizados dentro de las políticas públicas y dentro de muchos programas y servicios, consideran al Estado como una entidad lejana que no construye relaciones de cercanía ni confianza con las juventudes, por lo que se presenta una "cultura del maltrato" y esa lejanía, en el vínculo de relación, crea la percepción de un Estado que restringe derechos e invisibiliza la capacidad estratégica para el desarrollo de las y los jóvenes. A pesar de ello, existe la perspectiva de generar cambios desde el interior de la estructura estatal a través de acciones, grupales o individuales, por competencias profesionales o desde la vigilancia ciudadana y la incidencia política. 
Entrevistador: ¿Qué es para ti ser joven en el Perú?

L.T.: Como alguien que no sabe nada, una vez me acuerdo de que cuando fui a una institución a pedir apoyo [...] fui, hablé, me hice visible, hice todo, fui varias veces, estuve parado y me dijeron: «Pero tú simplemente eres un colectivo juvenil, eso no es nada para nosotros». Ellos solo apoyan a organizaciones grandes o a las ONG, pero a los colectivos juveniles los dejan de lado [...]. Creo que es porque piensan que el joven todavía no está preparado para poder asumir responsabilidades [...].

Desde la experiencia personal, las y los jóvenes relatan haber establecido vínculos de relación subordinada frente al mundo adultocéntrico e institucional-formal, específicamente con las autoridades políticas, en donde formar parte de un colectivo o grupo organizado no es suficiente para establecer relaciones de cooperación y articulación con la política formal; por el contrario, las y los jóvenes son adheridos a lógicas de jerarquías y subordinación que consideran a la juventud una etapa o periodo de «no definición», sin una posición en la estructura social y por ende, lejos de asumir responsabilidades y tareas del mundo adulto; incluso poco preparados para debatir en espacios formales dominados por las y los adultos.

S.Q.: La sociedad peruana es así, los padres mismos, cuando tú terminas de estudiar te dicen o a la academia a estudiar o a trabajar, entonces son estos clichés que los padres nos dicen... y ahí surge un problema porque muchos de los jóvenes en el grupo donde estoy, en un principio no han recibido el apoyo de sus padres [...].

Las y los jóvenes desarrollan sus patrones de socialización, identidad y relaciones con otros pares a través de la familia como primer espacio de reconocimiento a nivel individual y colectivo, es allí en donde se forman los procesos de integración a la sociedad, pero al mismo tiempo, y no de manera secuencial, estos procesos buscan la emancipación de la estructura familiar; algunas de esas trayectorias son el paso por la educación y la búsqueda de empleo. Si bien es cierto, la juventud es una construcción social y cultural, y no estrictamente un período biológico y de cambios físicos es inevitable el desarrollo de trayectorias educativas y laborales esperados por el entorno familiar, que en muchas ocasiones debe ser lo normativamente impuesto por la familia y que se insertan en relaciones de poder con el mundo adulto. Estas etiquetas del joven en transición lineal hacia el mundo adulto, a través del acceso a la educación y al mundo del trabajo, reducen otras dimensiones simbólicas a explorar como la participación, el uso de tecnologías, los vínculos en organizaciones, así como las mediaciones culturales a través de proyectos personales, expresando su condición diferenciada dentro de las sociedades en que se desenvuelven. 
S.Q.: Cada vez obtienen mayores liderazgos y se desarrollan más [...]. Eso es lo que cada joven busca, tal vez que te vean en la calle y digan: «Ah, él es el chico que trabaja en mi comunidad», entonces ese es el tema que muchos quieren lograr cuando son nuevos, dicen: «Yo quiero que, a donde voy, la gente me reconozca y sepa el trabajo que hago y lo hago sin necesidad de recibir algo a cambio, sino por la satisfacción de haberle cambiado algo en ellos». Creo que lo principal para enganchar a un joven es el protagonismo [...].

Las y los jóvenes que participan en organizaciones, colectivos juveniles y otras formas de asociación colectiva son sujetos insertos en procesos de cambio y protagonismo dentro de sus espacios locales, cuya finalidad es el vínculo con la comunidad y el territorio. De la misma forma, son jóvenes que buscan la obtención de objetivos en la vida cotidiana, en el corto y mediano plazo; la relación que se establece con el territorio es para generar cambios a través de la acción organizada y en base a carencias institucionales o prácticas formales insuficientes, mientras que el reconocimiento viene desde dos frentes: por un lado a través de la propia construcción del yo individual y la autoidentificación de su vida individual y organizada; y por otro lado, el reconocimiento colectivo por parte de la comunidad en la que se interviene, lo que le brinda legitimidad a la o el joven como sujeto estratégico para el desarrollo local.

\section{b. Participación organizada}

La participación como derecho fundamental de la persona se inscribe dentro de los vínculos de relación con otros pares con los cuales se comparten significados de objetivos comunes vinculados a la vida cotidiana y al entorno, de hecho, la participación organizada es un medio para alcanzar fines concretos que tienen implicancias a nivel individual y colectivo. Las y los jóvenes se vienen construyendo dinámicas de participación caracterizadas por la conformación de redes, mesas de trabajo, asambleas y organizaciones informales vinculadas a sus territorios. Además, en el actual contexto de las sociedades informacionales y del acceso a nuevas tecnologías virtuales se intensifican las relaciones sociales más allá de la presencia física o del cara a cara (Berger y Luckmann, 2003), específicamente en las formas colectivas de organización y participación desde la virtualidad.

La participación juvenil se sustenta en distintas motivaciones, fines y mecanismos de acceso, en un sentido de identificación individual y de relación con otras personas para causar impactos en sus intervenciones. La participación organizada en espacios juveniles se constituye según las necesidades, niveles de organización, 
discursos y cohesión entre sus participantes quienes pueden servir para generar mecanismos de aprendizaje, solidaridad y cooperación; para luego incidir y producir cambios en el entorno de la comunidad, incluso en la promoción e integración a los procesos para el desarrollo.

Entrevistador: ¿Qué es la participación juvenil en organizaciones?

L.T.: Guau..., es la iniciativa de cada joven de querer de aprender, saber más, querer aportar más, «oye ese grupo me agrada porque hacen iniciativas o incidencia y quiero participar con ellos», el querer empoderarme, querer aprender, querer ayudar. L.S.: Eso es la importancia de pertenecer a un grupo, porque vas a poder enseñar y sensibilizar en diferentes temáticas, empoderar a las personas en formación de líderes y hacer incidencia política en el lugar.

La participación es un instrumento y mecanismo legal, que, si bien se encuentra institucionalizado, en la práctica tiene impactos en la vida individual y en las relaciones con los demás. Si bien es cierto, el incentivo simbólico a participar suele ser individual, el sistema de significados es relacional pues involucra motivaciones y prácticas que tienen efectos en los procesos de proyecto personal como el aprendizaje, la incidencia, la socialización e integración a los procesos de desarrollo.

La participación dentro de espacios organizados no solo gestiona fines racionales e instrumentales para obtener beneficios materiales o económicos, sino también para deconstruir la realidad aparentemente «natural» e institucional por múltiples realidades que develen las estructuras de poder existentes. El hecho de participar en una organización implica un conjunto de repertorios, conocimientos, prácticas, acceso a redes para construir lo público con otros grupos de pares, aquí la participación se representa como gerente de conocimiento y como parte activa de la democracia (Kliksberg, 1999), pues los actores y organizaciones son capaces de entender sus propias realidades y son quienes tienen una relación estrecha con sus respectivos contextos.

L.S.: Si uno quiere un cambio, uno para hacer participación política tiene que incidir tanto social como individualmente; haciendo políticas públicas vas a poder demostrar al Estado que tú también tienes la capacidad de poder ayudar.

L.S.: [...] el tema de las violaciones correctivas, el tema de violencia familiar, violencia sexual, las muertes violentas, crímenes de odio, ver tantas realidades, es como que te mueve y ves que necesitas hacer políticas públicas e incidir en tu comunidad, porque primero es educar a tu comunidad e informar para que puedas hacer participación. 
Entrevistador: ¿Qué fue lo que te enganchó y te llevó a participar de manera regular en tu organización?

S.Q.: Fue esa necesidad de ver en la gente con la que convivo. Yo decía: «esos niños se comportan así tal vez porque tienen esas necesidades o carecen de algo", yo veo y me pregunto si puedo hacer algo por ellos [...] porque en ellos puedo verme a mí mismo cuando era pequeño [...].

Los procesos de cambio no son secuencias lineales, sino rupturas dentro de contextos sociales e históricos que requieren iniciativas colectivas tanto para la incidencia política como social. Para otras y otros jóvenes entrevistados, la participación representa un mecanismo demostrativo hacia el Estado para visibilizar capacidades y demostrar que no solo se trata de jóvenes apáticos e indiferentes hacia lo público, sino que la capacidad de participar se construye, en primera instancia, dentro de la vida cotidiana lo que en lo personal tiene impacto. Tal como lo menciona L.S., el hecho de presenciar en distintos espacios situaciones de violencia física, sexual, crímenes y otros delitos, despierta la capacidad de indignación ante un vacío y carencia del accionar colectivo que no ha sido satisfecho por institucionales formales del Estado. Ante esas coyunturas, la participación ciudadana toma un rol protagónico para la organización de la comunidad en incidencia y vigilancia ciudadana. Además, la participación individual y colectiva se inscribe dentro de un sistema de sensibilidades y valores compartidos con otros grupos de pares, en el que el otro no es un objeto receptor ni pasivo a su propio contexto social, sino activo interlocutor para mejorar los procesos de vida en el entorno.

\begin{abstract}
S.Q.: La participación juvenil es muy importante porque nos permite a nosotros los jóvenes dejar de lado ese cliché que tenemos hacia los jóvenes que son unos vagos. Entonces, podemos quitar de esa manera ese cliché ayudando a los demás [...] trabajar, no sé, con los padres, con los niños, para así lograr nuestra meta que es cambiar y promover el desarrollo de ellos mismos. Entonces los jóvenes tenemos esa labor fundamental, de nosotros mismos con nuestras propias manos, o sea, con nuestras ideas, desarrollar, mejorar [...].
\end{abstract}

La participación dentro de espacios organizados también es un recurso para enfrentar el etiquetamiento social y el estigma juvenil de considerarlos como irreverentes, pasivos y que viven en un estado permanente de relajo. La participación de las juventudes no se basa exclusivamente en la incidencia dentro de grupos juveniles o dentro de las cohortes de edad propias de las juventudes, sino en la instalación de prácticas de relación con grupos generacionales adultos y espacios de socialización como las familias, el barrio o la propia comunidad local. Se trata de jóvenes que 
piensan y llevan a cabo la participación protagónica a partir de deficiencias institucionales que no fueron solucionadas desde el sistema formal de representación.

\section{Formas de relación entre jóvenes y autoridades políticas}

Las y los jóvenes, como sujetos diferenciados dentro de la estructura social, construyen itinerarios y estrategias de vinculación con las autoridades políticas de sus respectivas localidades y comunidades; sin embargo, las tipologías de relación y construcción de vínculos suelen ser heterogéneas y no libres de barreras, tanto personales como institucionales, propias del aparato formal y de las perspectivas de definición que desde el mundo adulto se diseña con las y los jóvenes.

Las relaciones establecidas con las autoridades políticas se desarrollan en sistemas de poder, pues se construye la imagen de las juventudes en base a intereses que en muchos casos son instrumentales, de jerarquía o como vínculos para generar relaciones de subordinación, o como sujetos para la consulta que legitime su rol como autoridad pública. Relaciones consultivas hacia las juventudes con fines de legitimidad, relaciones caracterizadas por la presencia de barreras burocráticas, relaciones y vínculos basados en la discriminación generacional, así como prácticas clientelares que se visibilizan a través de la gestión pública y son resaltados por medio del discurso de las y los jóvenes organizados.

F.H.: [...] Pero sí tengo que admitir que el alcalde nos escucha, si me dices cuál es la prioridad o lo que hace la diferencia con otros Consejos, el alcalde acá nos escucha [...].

Entrevistador: ¿Cuáles son los temas que tocan con el alcalde, que él considere prioritario para los jóvenes?

F.H.: Él nos deja hacer lo que queramos, o sea, me refiero a que le podemos proponer los proyectos que queramos, pero cada proyecto es bueno siempre y cuando lo ejecuten hasta el final y que las Gerencias les ayuden a ejecutarlos.

Entrevistador: ¿Cómo son las coordinaciones con algunos líderes municipales? S.Q.: Ya ha pasado que la misma municipalidad no ha podido apoyarnos por el tema de la coordinación, entonces como mejor alternativa fue recurrir a uno de ello, como la vez que recurrimos a la buena fe de un regidor para que nos pueda donar algo, facilitar algo, algún espacio o equipo [...].

Para jóvenes como F.H. y S.Q. la relación construida con sus autoridades políticas municipales, si bien no han sido confrontacionales, no se constituyen en relaciones 
plenamente autónomas respecto a la capacidad protagónica de incidencia y participación que las y los jóvenes pueden brindar dentro del sistema municipal; dicha la relación se basa en instancias consultivas para legitimar las funciones públicas de las autoridades, así como los programas y servicios que se puedan derivar de ellos, en estos casos la municipalidad como órgano de representación del territorio local actúa como soporte en logística, recursos humanos y apoyo material para la ejecución de los programas, proyectos y actividades de las organizaciones juveniles.

Sin embargo, la construcción de relaciones con las autoridades políticas es más personal que institucional, de hecho, el contacto con algún regidor o funcionario se basa en una agenda o plataforma juvenil en común o simplemente, en el contacto personal tangencial con estos funcionarios; por ejemplo, simpatías personales o iniciativas propias de las autoridades municipales para acercarse a las y los jóvenes organizados para actividades específicas.

Entrevistador: ¿Sientes que las instituciones brindan apoyo a las organizaciones juveniles?

L.T.: Creo que sí, pero piden demasiados requisitos que te impiden mucho... el tiempo, por ejemplo, debes tener un año para que te apoyen, debes tener un reglamento, porque seamos sinceros, hay muchos chicos que tienen la iniciativa, pero no tienen el estudio o esa manera de hacer un estatuto (...).

Entrevistador: ¿Cómo es la relación con la municipalidad?

S.Q.: Con la municipalidad siempre hay que estar al tanto, siempre exigiéndole, porque tal vez ellos no te pueden dar el dinero, pero sí las herramientas. Pero para conseguir esas herramientas hay que gestionar documentos, hay que llevarlos a mesa de partes, siempre estar ahí exigiendo, exigiendo para que te puedan ayudar.

A diferencia de la situación descrita, en algunos distritos no existe dicha fluidez en las relaciones construidas entre jóvenes y autoridades políticas locales, lo que evidencia que dicha relación está sostenida en posiciones políticas y en la forma con que se mira a las juventudes, sea como grupo en constante estado de riesgo, como grupo poblacional en tránsito hacia el mundo adulto y productivo, o como sujetos productores de transformaciones en sus propios entornos para socializar el poder.

Como lo relata L.T., una de las barreras que dificulta el vínculo de relación entre autoridades políticas y jóvenes organizados son las prácticas burocráticas dentro de las instituciones públicas, pues se exigen requisitos y trámites formales para acceder a espacios, materiales y servicios públicos que brinda la municipalidad, lo que termina desalentando la continuidad de ese vínculo. Por un lado, para las autoridades públicas una organización 
juvenil se debe formar a partir de una estructura organizacional formal que cumpla un conjunto de procesos y trámites como los estatutos y reglamentos que determinen su accionar; y por otro lado, para las y los jóvenes es que una organización juvenil debe trascender la estructura «formal» jerárquica y por el contrario, deben caracterizarse por relaciones horizontales, cuyos objetivos sean concretos en el corto plazo y que tengan implicancias en su vida cotidiana, pues dichos elementos burocráticos solicitados son complementos de la propia organización, pero no su constitución misma.

Entrevistador: ¿Has observado a jóvenes independientes con interés de sumarse a organizaciones en Lima Norte?

L.T.: No, tengo que hablar con la municipalidad a ver si me aceptan, para que me den un espacio de la juventud y no me hicieron caso, porque tuve el error de decirles que somos un colectivo LGTB [...] ahora comprendo que si vamos a entidades tan grandes como la muni, tengo que ir como un colectivo juvenil no como un colectivo LGTB, ahí van a apoyar [...] Yo casi me garro boca a boca con uno de los representantes, mis amigos me dicen: «no le digas que eres gay», pero eso no iba con mi filosofía de vida [...].

Las relaciones entre autoridades políticas y jóvenes organizados se redefinen constantemente, ya no basta con la propia identidad juvenil para etiquetar a este grupo poblacional como sujetos insertos en la categoría analítica de juventud, generalmente está asociada a la variable edad. Se visibilizan identidades asociadas al género y a la sexualidad como elementos distintos entre las y los jóvenes, de hecho las organizaciones y colectivos juveniles suelen identificarse en base a características específicas y reivindicativas de su vida cotidiana, lo cual enfrenta resistencias, tensiones y controversias en su relación con la institucionalidad formal.

Como lo expresa L.T., para establecer relación con sus autoridades públicas las y los jóvenes tienen que diseñar de forma ficticia estrategias para que la condición de juventud englobe de manera abstracta y contenga identidades particulares como el de la identidad de género, elemento que ha sido objeto de discriminación y vulnerabilidad desde el mundo adultocéntrico que subordina los mundos juveniles. Esto también involucra el proceso de individualización en las formaciones identitarias (Duárez, 2008) en el que se resalta que la individualización permite que la identidad se convierta en un proceso para las y los jóvenes, puesto que deben mantenerla en constante actuación, es importante recalcar que la identidad juvenil parte de un proceso de autopercepción y autoreconocimiento que permite identificar y diferenciar «un nosotros» de un conjunto de otras personas o grupos sociales. 
L.S.: [...] Como sabrás tenemos un Estado que tiene políticos que en realidad hacen politiquería, que no saben y están como funcionarios, o que no saben realmente las necesidades o no saben manejar esas carencias... siento impotencia, habiendo otros profesionales que bien podrían manejar y articular en esos espacios, pero como bien sabrás, hay también los favores políticos que están en educación y salud, y pagan, meten a cualquiera en esos puestos [...]. Como experiencias más cercanas, conversando con algunos compañeros, me dicen que prefieren no trabajar en el Estado, que no hay buen pago, que son corruptos o que no hacen nada [...], prefieren trabajar en entidades particulares, porque piensan que tienen alcances más amplios o llegan a la comunidad de forma más rápida [...].

Existen miradas más generalizadas y abstractas desde las y los jóvenes organizados y no organizados que consideran al Estado como una estructura burocrática-formal asediada por prácticas clientelares y cuyas autoridades políticas, encargadas del diseño e implementación de políticas, programas y servicios hacia las juventudes, no presentan habilidades y capacidades meritocráticas; por el contrario, se basan en «favores políticos» y cuya posición dentro de la estructura estatal está sostenida por redes clientelares y por contactos amicales. El Estado es percibido, entonces, como una entidad ajena a las demandas e intereses de las juventudes, en donde alcanzar carreras meritocráticas quedan frustradas por la presencia de la corrupción, prácticas clientelares y la propia burocratización del sistema.

\section{Espacios institucionalizados de participación juvenil}

Las y los jóvenes organizados desarrollan y ponen en práctica sus sentidos de participación dentro de espacios en donde se puedan sentir apreciados y liberen sus potencialidades de transformación personal y colectiva. Existen diversas modalidades de agrupamiento colectivo con presencia juvenil como mesas juveniles de trabajo, grupos informales culturales y de producción artística, asociaciones locales y vecinales con fuerte componente territorial y cuya incidencia está a cargo de jóvenes que le brindan significado y sentido de pertenencia a sus territorios.

Sin embargo, para fines analíticos, los espacios institucionalizados o formales de participación juvenil se desarrollan en un sistema de poder jerárquico que involucra las demandas heterogéneas de las juventudes y las visiones del mundo adulto, donde las y los jóvenes se construyen en base a condiciones diferenciadas y se encuentran insertos en lógicas de integración a los procesos para el desarrollo y subordinación por medio de estrategias adultocéntricas. 
Las relaciones de poder existentes, dentro de los espacios de participación juvenil, se acentúan y evidencian más según la perspectiva política y tratamiento que las autoridades públicas construyen en torno a la imagen de la o el joven, en donde se visibilizan y reconocen jóvenes como sujetos de derechos con participación protagónica para el desarrollo, jóvenes sin vínculo con otros grupos generacionales en los espacios de participación, jóvenes participantes en espacios formativos o incluso espacios juveniles sostenidos por el propio Estado.

Entrevistador: ¿Qué te parece la implementación de los Consejos de Juventud? J.C.: Me parece importante, pero creo que en realidad no se le toma en serio porque tienen una participación en organización, hay una resolución a favor de los Consejos, pero solo se reúnen los Consejos sin sus autoridades... por eso pienso que los reconocen en parte, pero no les dan su respaldo, no hay un presupuesto $[\ldots]$ tampoco hay proyectos [...] pero si veo que hay un Consejo en mi distrito que tiene el respaldo de su municipalidad, tendría más voluntad de ir porque veo que la municipalidad le está dando un respaldo [...].

Existen espacios de participación institucionalizados por las municipalidades locales como los Consejos Distritales de Juventud, instancias articuladoras de organizaciones juveniles y de carácter territorial que, en teoría, deberían constituirse en órganos de representación juvenil ante las autoridades públicas distritales; sin embargo, en primer lugar no todos los Consejos Distritales de la Juventud a nivel distrital están implementados, ni tienen sostenibilidad a través de las gestiones municipales y no todos cumplen la función de vigilancia, incidencia y representación juvenil a nivel territorial.

Como lo expresa el entrevistado J.C., el reconocimiento de este espacio de participación se remite solo a lo normativo-formal sin trascender dicho sistema para un real compromiso en la relación autoridades-juventudes. El reconocimiento formal es solo parte del proceso de trabajo con jóvenes organizados y el Consejo, como espacio de participación juvenil institucionalizado, es traductor de las demandas juveniles transformándolas en propuestas coherentes y ejecutables, pero según algunos testimonios, existen consejos de juventudes que no generan articulaciones con sus propias autoridades, siendo instancias estrictamente juveniles y no intergeneracionales, tal como deberían constituirse para el diseño y ejecución de proyectos, programas y servicios para las y los jóvenes, esto también se sustenta en el paradigma de considerarlos sujetos para la consulta y legitimación de las políticas públicas que se buscan aprobar desde el sector público. 
Entrevistador: Entrando a los espacios institucionalizados como el CMPJ o el CDPJ ¿Cómo ves la situación de estos espacios?

L.S.: Los veo como espacios formativos de alianzas, de tener a los jóvenes en diferentes agrupaciones, ya están casi en una red. Esta institución pueda formarlos también, es como tener sociedad civil con Estado [...].

Espacios de participación juvenil como el Consejo Metropolitano de Participación de la Juventud (CMPJ) o los propios Consejos Distritales de la Juventud (CDJ) también representan espacios formativos para el desarrollo de proyectos personales, así como de incidencia, vigilancia ciudadana y aspectos de la vida social, pues las y los jóvenes producen sentidos y significados basados en su pertenencia al colectivo, un híbrido entre la oferta que pueden recibir por parte del Estado a través de programas y servicios, y la formación que organizados brindan a otros jóvenes a través de estos espacios de participación, formando una cadena-red entre sociedad civil y aparato estatal.

Entrevistador: ¿Quiénes creen que deben impulsar y llevar adelante el Consejo Juvenil?

S.Q.: Dos actores importantes: nosotros mismos como organización y el tema de la municipalidad, el gobierno y el Estado que también deben impulsar y apoyar todo eso. Nosotros mismos con nuevas ideas y la municipalidad o el gobierno con el sustento de todo esto.

Los Consejos Distritales de Juventud no son espacios juveniles autocontenidos y autosostenidos por las y los jóvenes involucrados en su gestión, por el contrario, se necesita de la articulación, participación y gestión de un conjunto de actores; por un lado, las y los jóvenes del territorio local, quienes le dan visibilidad pública al espacio y suman esfuerzos para articularse con otros espacios juveniles e intergeneracionales que ejecuten proyectos, programas y servicios municipales o de instituciones privadas; y por otro lado, al Estado como actor estratégico que brinda viabilidad y posterior sostenibilidad al diseño e implementación de los Consejos Distritales de la Juventud, estos representados por las municipalidades distritales quienes deben ser el soporte institucional, económico y de gestión que canalice las demandas para su conversión en propuestas programáticas para las juventudes.

\section{Conclusiones}

Las y los jóvenes como actores dentro de las sociedades no tienen una exclusiva definición ni una vía analítica homogénea para poder comprenderlos desde sus propias experiencias, vivencias y significados. Esta investigación ha intentado brin- 
dar abordajes y reflexiones sobre las y los jóvenes como actores estratégicos para el desarrollo y sujetos de derechos, con un conjunto de demandas heterogéneas entre unos y otros, insertos dentro de espacios de lucha y de poder hacia otros grupos como el mundo adulto y las autoridades políticas de las gestiones locales.

Las y los jóvenes son agentes activos con similitudes y diferencias en sus propios proyectos personales y colectivos, no se reducen exclusivamente a paradigmas que los consideran como grupos en situación de vulnerabilidad y riesgo, grupos en moratoria social, sujetos jóvenes que son preparados para el tránsito al mundo adulto y la vida productiva; si bien estos paradigmas han sido recurrentes bajo las lógicas de las políticas públicas estatales, especialmente cuando se busca su integración a la sociedad, no son los únicos; por ello, una salida analítica es tomar a las y los jóvenes a través de sus propias condiciones juveniles de existencia, esto quiere decir que se encuentran insertos dentro de lógicas complejas y muchas veces contradictorias entre la búsqueda de la emancipación y la integración subordinada a los procesos para el desarrollo.

Las y los jóvenes se insertan en tramas de significados y luchas de poder frente al mundo adultocéntrico, este último considerado un sistema de prácticas institucionalizadas que busca imponer su producción de conocimiento como hegemónico, invisibilizando a las diversas condiciones de hacerse joven, que como se ha dicho no se reduce a la transición a la vida adulta ni a un periodo biológico.

Existen diversas formas de hacerse joven como construcción social y cultural, y a través de diversos mecanismos como la socialización con los pares, el aprendizaje y la propia transición hacia la vida adulta; si bien las y los jóvenes presentan opiniones críticas en torno a las distintas formas de construir al sujeto juvenil, son miradas basadas en el contexto de relaciones de poder existentes, desde aquellas lógicas adultocéntricas hasta aquellas perspectivas que toman en cuenta a los agentes familiares como elementos para autodefinirse y construirse como joven.

Respecto a la participación juvenil organizada, esta es un medio expresado dentro de un sistema de relaciones sociales, cuyas motivaciones y prácticas de realización tienen implicancias e impactos en los proyectos personales y colectivos de las y los jóvenes, además esta investigación ha reflexionado, a través de los discursos y testimonios mostrados, que la participación juvenil es un incentivo simbólico para generar espacios de aprendizaje, solidaridad y cooperación, y ha permitido visibilizar las estructuras de poder en la relación entre el aparato estatal y la sociedad civil.

Por otro lado, la participación llevada a cabo por las y los jóvenes organizados, busca generar rupturas en las continuidades del orden existente a través de la incidencia y vigilancia, pero no se pretende considerar a las juventudes dentro de la categoría reserva moral de la sociedad, sino como sujetos que buscan cambios 
en el entorno local, donde sus prácticas (Ilamadas «informales») de participación buscan penetrar las estructuras formales de representación. Según los discursos recogidos, la participación puesta en marcha por las y los jóvenes organizados sirve como recurso para enfrentar procesos de vulnerabilidad según identidades, estigmatizaciones y carencias institucionales.

Las relaciones entre jóvenes y autoridades políticas locales han sido tensas, complejas y sostenidas por un conjunto de barreras, por un lado a través de la presencia y el ejercicio de prácticas adultocéntricas que buscan controlar y subordinar a las juventudes, en muchos casos a través de la discriminación por identidad. A nivel institucional, las y los jóvenes entrevistados han identificado barreras burocráticas hacia la gestión municipal, prácticas clientelares que fragmentan la relación con el Estado a escala local, lo que los ha llevado a tomarla como una entidad abstracta, lejana en la empatía y compromiso con sus demandas. Aún falta avanzar en el reconocimiento de las y los jóvenes como actores estratégicos para el desarrollo y no solo como sujetos para la consulta que sustente la legitimidad de las autoridades locales.

Los espacios de participación juvenil deben ser intergeneracionales para el debate público, además deben estar articulados a las estructuras de la burocracia local como las municipalidades y los órganos que trabajan competencias en materia de juventudes, porque es allí donde las organizaciones juveniles son canalizadoras y traductoras de las demandas juveniles en plataformas técnicas y políticas que incorporen los planes, servicios y proyectos dirigidos a las juventudes.

Los espacios de participación no deben representar campos autocontenidos ni que su articulación sea estrictamente con otros colectivos juveniles que lleve a la juvenilización de la sociedad, por el contrario, según testimonios recogidos, deben ser plataformas viables y sostenibles a través del soporte estatal y del impulso de las y los jóvenes que generen consensos para la implementación de políticas públicas no solo para juventudes, sino también generacionales y sectoriales. Ello permitirá que las políticas diseñadas e implementadas sean desde las juventudes, para las juventudes y con las juventudes como agentes transformadores de sus realidades.

\section{Bibliografía}

AguiRRE-GARCíA, J. y JARAmillo-ECHEVERRI, L. (2012). Aportes del método fenomenológico a la investigación educativa. Revista Latinoamericana de Estudios Educativos, 8(2), 51-74. Recuperado de https://www.redalyc.org/pdf/1341/134129257004.pdf 
Alvarado, S.; Borelli, S. y Vommaro, P. (Editores) (2012). Jóvenes, políticas y culturas: experiencias, acercamientos y diversidades. Buenos Aires, Argentina:CLACSO HomoSapiens Ediciones.

Alvarado, S.; MARTínEZ, J. y MuÑOZ, D. (2009). Contextualización teórica al tema de las juventudes: una mirada desde las ciencias sociales de la juventud. Revista Latinoamericana de Ciencias Sociales, Niñez y Juventud, 7(1), 83-102. Recuperado de http://www. redalyc.org/articulo.oa?id=77307104.

BALARDINI, S. (2005). ¿Qué hay de nuevo viejo?: una mirada sobre los cambios en la participación política juvenil. Nueva Sociedad, (200), 96-107. Recuperado de: https://nuso. org/articulo/que-hay-de-nuevo-viejo-una-mirada-sobre-sobre-los-cambios-en-laparticipacion-juvenil/.

BERGER, P. y LUCKMANN, T. (2003). La construcción social de la realidad. Buenos Aires, Argentina: Amorrortu.

Botero, P. y ToRRES, J. (2008). Perspectivas teóricas para comprender la categoría participación ciudadana - política juvenil en Colombia. Revista Latinoamericana de Ciencias Sociales, Niñez y Juventud, 6(2), 565-611. Recuperado de http://www.redalyc.org/ articulo.oa?id=77360205.

BouRdiEU, P. (2002). La «juventud» no es más que una palabra. Sociología y cultura (pp. 163-173). México: Grijalbo, Conaculta.

CAMPoy, T. y Gomes, E. (2015). Técnicas e instrumentos cualitativos de recogida de datos. En A. Pantoja. (Coordinador), Manual básico para la realización de tesinas, tesis y trabajos de investigación (pp. 275-300). Madrid, España: EOS.

CASTELLANOS, J. (2011). La condición juvenil: opciones metodológicas para la construcción de un objeto de conocimiento. En G. Muñoz González. (Editor), Jóvenes, culturas y poderes (pp. 161-187). Bogotá, Colombia: Siglo del Hombre Editores.

CENTRO DE DeSARRollo DE LA OCDE (2017). Estudio de bienestar y políticas de juventud en el Perú. París, Francia: Proyecto OCDE-UE.

DÁVILA, O.; GHIARDO, F. y MEDRANO, C. (2008). Los desheredados. Trayectorias de vida y nuevas condiciones juveniles. Valparaíso, Chile: Ediciones CIDPA.

DÁVILA, O. y GHIARDO, F. (2011). Condiciones juveniles: estructuras de transición y trayectorias. Revista de Sociología UNMSM, (20), 43-58.

DUÁREZ, J. (2008). A propósito de pertenecer y ser un@ mism@: jóvenes, experiencias organizativas, autonomías personales y posibilidades para la ciudadanía en Villa El Salvador. Debates en Sociología, (33), 95-116. Recuperado de http://revistas.pucp.edu.pe/index. php/debatesensociologia/article/view/2543/2487. 
DUARTE, K. (2000). ¿Juventud o Juventudes? Acerca de cómo mirar y remirar a las juventudes de nuestro continente. Última Década, 8(13), 59-77. doi: 10.4067/S071822362000000200004.

GARCÉS, Á. (2010). De organizaciones a colectivos juveniles panorama de la participación política juvenil. Última Década, (32),61-83. doi: 10.4067/S0718-22362010000100004. GURDIÁN-FERNÁNDEZ, A. (2007). El paradigma cualitativo en la investigación socio-educativo. San José, Costa Rica: Coordinación Educativa y Cultural Centroamericana (CECC) y Agencia Española de Cooperación Internacional (AECI).

HOPENHAYN, M. (1988). La participación y sus motivos. Santiago de Chile. Recuperado de https://www.academia.edu/11397202/_LA_PARTICIPACI\%C3\%93N_Y_SUS_MOTIVOS_.

KLIKSBERG, B. (1999). Seis Tesis no convencionales sobre participación. Revista de Estudios Sociales, (4). Recuperado de http://www.redalyc.org/articulo.oa?id=81511266010. KRAUSKOPF, D. (2000). Dimensiones críticas en la participación social de las juventudes. En S. Balardini. (Comp.), La participación social y política de los jóvenes en el horizonte del nuevo siglo (pp. 119-134). Buenos Aires, Argentina: FLACSO.

KRIEGER, M. (2003). Sociología de las organizaciones. México: PH.

ORTIZ-RUIZ, N. (2016). ¿Qué mueven a las organizaciones juveniles? Revista Latinoamericana de Ciencias Sociales, Niñez y Juventud, 14(1), 531-543. Recuperado de http://www. scielo.org.co/pdf/rlcs/v14n1/v14n1a37.pdf.

SANDOVAL, M. (2000). La relación entre los cambios culturales de fines de siglo y la participación social y política de los jóvenes. En S. Balardini (Comp.), La participación social y política de los jóvenes en el horizonte del nuevo siglo (pp. 147-164). Buenos Aires, Argentina: CLACSO.

SENAJU (2013). Instructivo para la implementación de espacios de participación juvenil. Lima, Perú: Secretaría Nacional de la Juventud.

Souto, S. (2007). Juventud, teoría e historia: la formación de un sujeto social y de un objeto de análisis. Historia Actual Online, (13), 171-192. Recuperado de https://dialnet.unirioja. es/servlet/articulo?codigo $=2479343$.

SouzA, M. (2010). Los conceptos estructurantes de la investigación cualitativa. Salud Colecti$v a, 6(3), 251-261$. Recuperado de https://www.redalyc.org/articulo.oa?id=73115348002

TAGUENCA, J. (2009). El concepto de juventud. Revista Mexicana de Sociología, 71(1), 159190. Recuperado de https://www.redalyc.org/pdf/321/32116011005.pdf.

VALENZUELA, K. (2007). Colectivos juveniles: inmadurez política o afirmación de otras políticas posibles. Última Década, (26), 31-52. doi: 10.4067/S0718-22362007000100003.

VEGA, M. y EsCALANTE, K. (2007). Organizaciones juveniles: ¿espacios de formación ciudadana? Signo y Pensamiento, 26(51), 150-159. Recuperado de http://www.redalyc.org/ articulo.oa?id=86005114. 